\title{
Evidence for a recent change in the link between the North Atlantic Oscillation and Arctic sea ice export
}

\author{
Michael Hilmer and Thomas Jung \\ Institut für Meereskunde an der Universität Kiel, Germany
}

\begin{abstract}
Evidence for a recent change in the link between the North Atlantic Oscillation (NAO) and Arctic sea ice export through Fram Strait during wintertime (DJFM) is presented from the analysis of simulated Arctic sea ice and observations for the period 1958-1997. Whereas no correlation between the two time series is found from 1958 to $1977(\mathrm{r}=0.1)$, the correlation increased significantly thereafter $(r=0.7,1978-1997)$. The increased coherency between the NAO and Arctic sea ice export through Fram Strait during the last two decades resulted from anomalous meridional wind components near Fram Strait which were associated with the more easterly position of the NAO's centers of interannual variability compared to 1958-1977.
\end{abstract}

\section{Introduction}

Recent studies indicate that the Atlantic thermohaline circulation is sensitive to freshwater intrusions in high latitudes [e.g., Rahmstorf, 1994; Mauritzen and Häkkinen, 1997]. This may have substantial effects on the climate in the North Atlantic region. Sea ice volume flux out of the Arctic through Fram Strait represents a major source of freshwater [Aagaard and Carmack, 1989; Hilmer et al., 1998]. The North Atlantic Oscillation (NAO) is the dominant atmospheric mode of variability in the North Atlantic region and describes the simultaneous strengthening (high NAO) and weakening (low NAO) of the Azores High and Icelandic Low of surface pressure [e.g., Hurrell, 1995]. Relatively less is known about its link to the ice volume flux through Fram Strait because of the shortness of observed sea ice time series. Recent studies indicate a high positive correlation between the NAO and estimates of the ice area flux ( $\mathrm{r}=0.66 ; 1978-1996)$ [Kwok and Rothrock, 1999] as well as the parameterized ice volume flux $(r=0.77 ; 1976-1996)$ [Dickson et al., 2000] during wintertime. Estimates of the ice volume flux, however, suffer from sparse ice thickness observations prior to the early 1990s [Vinje et al., 1998]. Here, we present evidence that the link between the NAO and Arctic sea ice export through Fram Strait underwent secular changes during the last forty years.

\section{Results}

To study the link between the NAO and the Fram Strait ice volume export we used a dynamic-thermodynamic sea ice model forced by a climatological ocean and realistic atmospheric fields of daily near-surface wind speed and air

Copyright 2000 by the American Geophysical Union.

Paper number 1999GL010944.

0094-8276/00/1999GL010944\$05.00 temperature for the period 1958-1997. Details on the simulation are given in Hilmer et al. [1998]. The modelled sea ice export through Fram Strait is solely a function of the southward drift speed (SDS) and thickness (h) of sea ice in the Fram Strait [e.g., Harder et al., 1998]. Sea level pressure (SLP) fields from the NCEP/NCAR reanalysis [Kalnay et al., 1996] and the NAO index are used to determine the link to the atmosphere. Here, the NAO index is defined as the difference between the normalized SLP time series from the Azores and Iceland [Rogers, 1984]. The focus is on the winter season (December-March) when interannual variability of the NAO and Arctic sea ice export are most pronounced.

Time series of modelled and observed sea ice exports through Fram Strait are depicted in Fig. 1 together with the NAO index. The simulated ice area flux is in very good agreement $(r=0.88)$ with satellite-based estimates from Kwok and Rothrock [1999] during the overlapping period 1978-1996. A combination of sea ice drift and thickness measurements provides estimates of the sea ice volume flux [Vinje et al., 1998] for the period 1990-1996. Except for the winter $92 / 93$ simulated and observed values are in fair agreement. Mainly SDS and to a lesser extent $h$ contributes to the variability of ice volume flux through Fram Strait; correlations between SDS and $h$ are relatively small (Tab. 1).

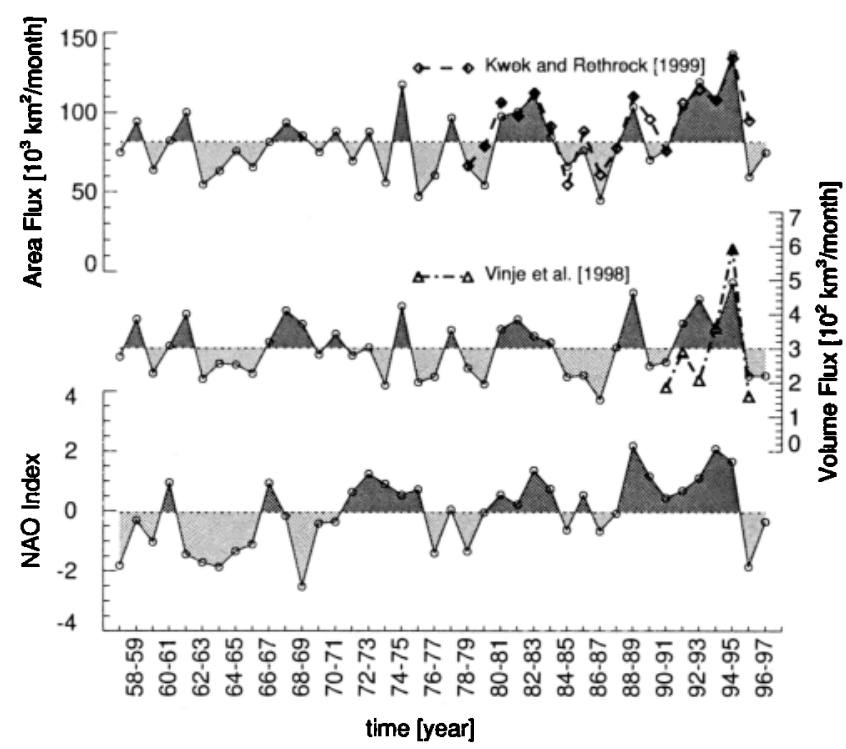

Figure 1. Time series of observed and simulated sea ice quantities in Fram Strait and observed NAO index for the winterseason (DJFM). From top to bottom: (1) modelled ice area flux (solid) and satellite-based estimates [Kwok and Rothrock, 1999] (dashed); (2) modelled (solid) and observed [Vinje et al., 1998] (dash dot) ice volume flux; (3) NAO index. Dotted lines represent long-term mean values for the period 1958-1997. 


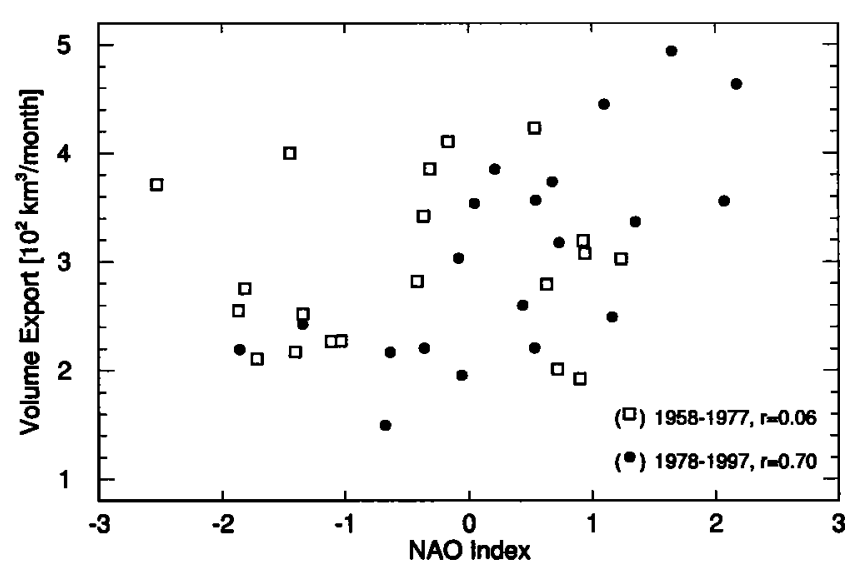

Figure 2. Modelled ice volume flux through Fram Strait versus observed NAO index during the winterseasons 1958-1977 (open squares) and 1978-1997 (solid circles).

In agreement with the observational estimates [Kwok and Rothrock, 1999], the NAO explains about $50 \%\left(r^{2} \cdot 100\right)$ of the ice volume export variability during the period 19781997 (P2 hereafter); the moderate correlation between the two time series for the whole period (1958-1997, $r=0.4)$ may be explained by a missing link during the period 1958-1977 (P1 hereafter)(Tab. 1; Fig. 2). Primarily changes in the correlation between the NAO and SDS are responsible for these differences (Tab. 1).

So far, the separation of the whole time series into P1 and P2 is motivated by the comparibility with previous studies. To shed further light onto the time dependence of the link between the NAO and Arctic sea ice export, wavelet co-spectra were estimated (Fig. 3). In-phase variability between the two time series increased markedly after the late seventies. The same analysis was repeated using Paul wavelets (not shown), which allow for a better resolution in the time domain compared to Morlet wavelets [Torrence and Compo, 1998]. Since the gross features of the wavelet co-spectrum are not very sensitive to side effects, the wavelet analysis yields additional support for the separation into P1 and P2.

The anomalous SLP patterns associated with anomalously high modelled ice volume transport through Fram Strait (Fram pattern) for the period 1958-1997 and with the NAO indices for the two subperiods $\mathrm{P} 1$ and P2 are

Table 1. Correlation statistics for the NAO index and different modelled sea ice quantities in Fram Strait (DJFM). Two different epochs are considered: 1958-1977/1978-1997.

\begin{tabular}{lccc}
\hline & Ice Volume Flux & SDS $^{a}$ & $\mathbf{h}^{b}$ \\
\hline NAO & $0.06 / 0.70^{*}$ & $0.14 / 0.73^{*}$ & $-0.32 / 0.27$ \\
SDS $^{a}$ & $0.94^{*} / 0.93^{*}$ & $1.0^{*}$ & $0.32 / 0.39$ \\
$\mathrm{~h}^{b}$ & $0.59^{*} / 0.69^{*}$ & $0.32 / 0.39$ & $1.0^{*}$ \\
\hline
\end{tabular}

${ }^{a}$ Southward driftspeed of ice through Fram Strait.

${ }^{b}$ Ice thickness in Fram Strait.

* Correlations significant at the $95 \%$ confidence level based on a two-sided $t$-test, taking serial correlation into account. shown in Fig. 4. The Fram pattern (Fig. 4c) is characterized by anomalously low SLP in the Barents Sea, leading to an anomalous southerly flow near Fram Strait and, therefore, to high ice exports through Fram Strait. During P1 the primary center of the northern cell of the NAO was located near the southern tip of Greenland (Fig. 4a). No anomalous southerly wind component was present near Fram Strait to affect the ice volume flux. Interannual NAO variability intensified in the Barents Sea region and over the Iberian Peninsula during P2, whereas SLP anomalies decreased further westward (Fig. 4b). This eastward shift of the NAO-related SLP variability led to a pronounced anomalous southerly wind component between Greenland and Spitzbergen and, therefore, to in-phase variability between the NAO index and the ice volume flux through Fram Strait on interannual time scales (Fig. 2,3). Moreover, this shift affected the ice volume exports through Denmark Strait and Davis Strait: Whereas the time dependence of the link between the NAO and ice export through Denmark Strait $(r=0.01$ for $P 1$ and $r=0.69$ for $P 2)$ is similar to those for the Fram Strait, the correlation between the NAO and ice export through Davis Strait was much more pronounced during P1 $(r=0.63)$ compared to $P 2(r=0.13)$.

The eastward displacement of the NAO's centers of interannual variability from $P 1$ to $P 2$ is presumably not an artifact due to sampling problems over the Arctic, since the largest differences between the SLP patterns occur close to Scandinavia and Greenland (Fig. 4d), i.e., over relatively well-sampled areas. We have repeated the same analyses using an updated version of the SLP data set described in Trenberth and Paolino [1980]; the changes are essentially the same as those shown in Fig. 4d.

\section{Discussion}

It is shown that the link between the NAO and simulated Arctic sea ice export through Fram Strait on interannual time scales underwent secular changes during the last four decades. From the data used in this study, however, it can-

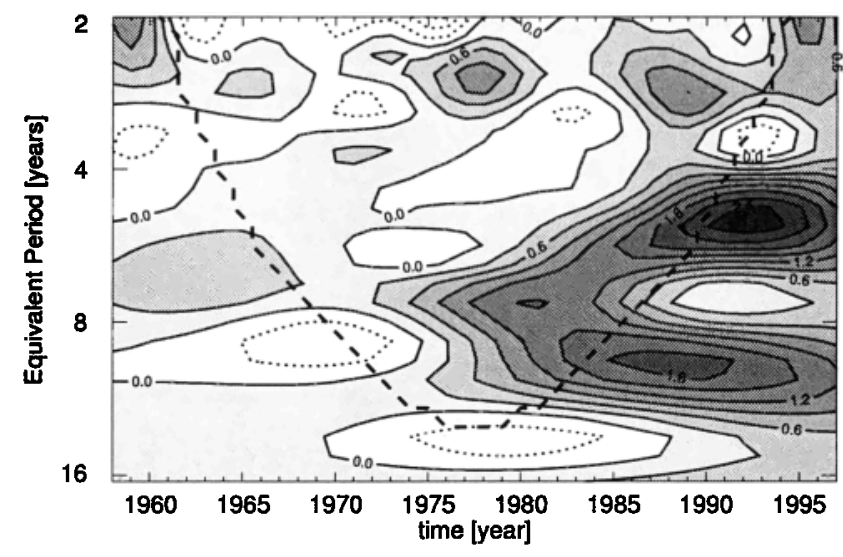

Figure 3. Local wavelet co-spectra $\left(10^{2} \mathrm{~km}^{3} / \mathrm{month}\right)$ during wintertime (DJFM) between the observed NAO index and simulated sea ice export through Fram Strait. The wavelet co-spectra are based on Morlet wavelets calculated as described in Torrence and Compo [1998]. The co-spectra give the local strength of inphase $\left(0^{\circ}\right.$, positive values) and out-of-phase $\left(180^{\circ}\right.$, negative values) variability between both time series in the plane of equivalent period $(\approx$ period) versus time. Estimates within the cone of influence (dashed) are influenced by side-effects. 

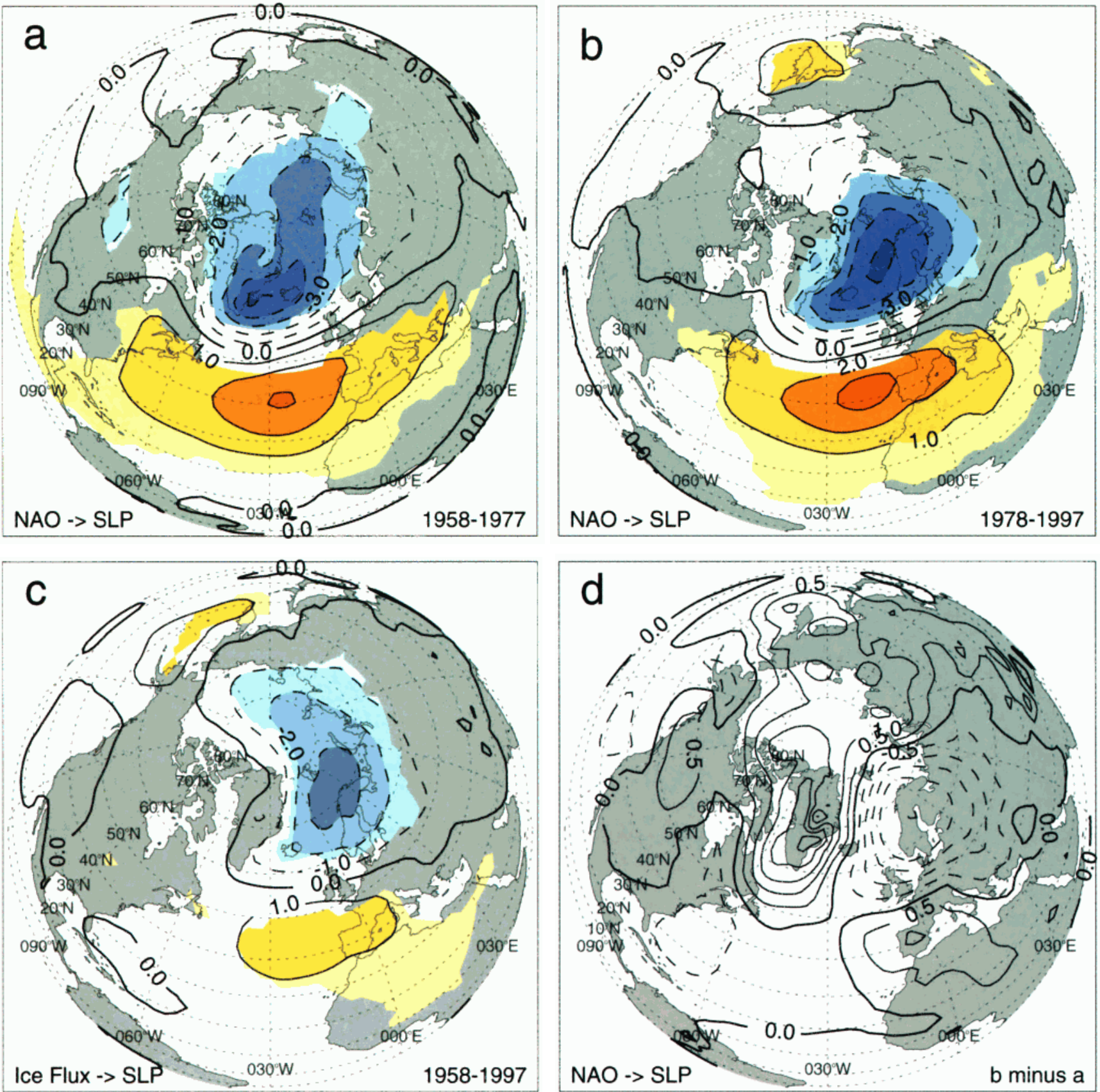

Figure 4. SLP anomalies ( $h P a$ ) associated with the NAO index during (a) 1958-1977 and (b) 1978-1997, and (c) with the time series of modelled ice volume export through Fram Strait over the full period 1958-1997. Anomalous SLP fields were regressed onto the normalized time series. Statistically significant slope parameters (95\% confidence level) are colored. Contour interval is $1 \mathrm{hPa}$. (d) Difference of the NAO-related anomalous fields of SLP, (b)-(a), between the periods 1978-1997 and 1958-1977. Contour interval is $0.5 \mathrm{hPa}$. Linear trends were removed prior to the analyses. The standard deviations of the detrended NAO indices for the periods $\mathrm{P} 1$ and $\mathrm{P} 2$ are nearly equal. 
not be decided whether the NAO and Arctic sea ice export are significantly related in a long-term context. This question might be addressed by analysing historical SLP data and long integrations of realistic coupled general circulation models (CGCMs).

The observed secular changes in the longitudinal position of the centers of interannual NAO variability raise some questions, which may be of importance well beyond the main topic of this study:

- Did the atmospheric change result from a change in the occupation statistics of fixed modes [Corti et al., 1999], rather than from a shift in the position of a natural mode of variability (NAO)?

- Are changes in the longitudinal position of the NAO common features of the North Atlantic climate system? Note, that Ulbrich and Christoph [1999] found a northeastward shift of the NAO's northern center of variability under increasing greenhouse gas forcing in a CGCM. This is in contrast to the control integration, where the centers of NAO variability were rather fixed.

- Around the mid-seventies, when the change in the longitudinal position of interannual NAO variability was presumably most pronounced, the NAO changed towards its interdecadal high state [Hurrell, 1995]. Is this connection purely accidental?

- Are there any effects on the North Atlantic ocean and regional climates of the neighbouring continents?

Acknowledgments. We thank E. Ruprecht, P. Lemke, A. Meyer, and two reviewers for helpful comments on earlier versions of the manuscript. This is a contribution of the Sonderforschungsbereich 460 "Dynamics of Thermohaline Circulation Variability" at the University Kiel supported by the German Research Foundation. NCEP/NCAR Reanalysis data were provided through the NOAA Climate Diagnostics Center (http://www.cdc. noa.gov/).

\section{References}

Aagaard, K., and E. C. Carmack, The role of sea ice and other freshwater in the Arctic circulation. J. Geophys. Res., 94, 305$311,1989$.
Corti, S., F. Molteni, and T. N. Palmer, Signature of recent climate change in the frequencies of natural atmospheric circulation regimes. Nature, 398, 799-802, 1999.

Dickson, R. R., T. J. Osborn, J. W. Hurrell, J. Meincke, J. Blindheim, B. Adlandsvik, T. Vinje, G. Alekseev, and W. Maslowski, The Arctic response to the North Atlantic Oscillation. J. Climate, in press, 2000.

Harder, M., P. Lemke, and M. Hilmer, Simulation of sea ice transport through Fram Strait: Natural variability and sensitivity to forcing. J. Geophys. Res., 103, 5595-5606, 1998.

Hilmer, M., M. Harder, and P. Lemke, Sea ice transport: A highly variable link between Artic and North Atlantic. Geophys. Res. Lett., 25, 3359-3362, 1998.

Hurrell, J. W., Decadal trends in the North Atlantic Oscillation: Regional temperatures and precipitation. Science, 269, 676$679,1995$.

Kalnay, E., et al., The NCEP/NCAR 40-year reanalysis project. Bull. Amer. Meteor. Soc., 77, 437-470, 1996.

Kwok, R., and D. A. Rothrock, Variability of Fram Strait ice flux and North Atlantic Oscillation. J. Geophys. Res., 104, 5177-5189, 1999

Mauritzen, C., and S. Häkkinen, Influence of sea ice on the thermohaline circulation in the Arctic-North Atlantic ocean. Geophys. Res. Lett., 24, 3257-3260, 1997.

Rahmstorf, S., Rapid climate transitions in a coupled oceanatmosphere model. Nature, 372, 82-85, 1994.

Rogers, J. C., The association between the North Atlantic Oscillation and the Southern Oscillation in the Northern Hemisphere. Mon. Wea. Rev., 112, 1999-2015, 1994.

Torrence, C., and G. P. Compo, A practical guide to wavelet analysis. Bull. Amer. Meteor. Soc., 79, 61-78, 1998.

Trenberth, K. E., and D. A. Paolino, The Northern Hemisphere sea-level-pressure data set: Trends, errors and discontinuities. Mon. Wea. Rev., 108, 855-872, 1980.

Ulbrich, U., and M. Christoph, A shift of the NAO and increasing storm track activity over Europe due to anthropogenic greenhouse gas forcing, Clim. Dyn., 15, 551-559, 1999.

Vinje, T., N. Nordlund, and $\AA$. Kvambekk, Monitoring ice thickness in Fram Strait. J. Geophys. Res., 103, 10437-10449, 1998.

M. Hilmer and T. Jung, Institut für Meereskunde an der Universität Kiel, Düsternbrooker Weg 20, D-24105 Kiel, Germany (e-mail: mhilmer@ifm.uni-kiel.de; tjung@ifm.uni-kiel.de)

(Received July 23, 1999; revised February 3, 2000; accepted February 7, 2000.) 